\title{
Evaluation of histopathological on maedi disease with serological confirmation in North-East of Iran
}

\author{
Farhang Sasani ${ }^{1 *}$, Javad Javanbakht ${ }^{1}$, Farhid Hemmatzadeh², Mehdi R.Moghadam ${ }^{3}$ and Mehdi A.Mohammad Hassan ${ }^{4}$ \\ *Correspondence: Fsasani@ut.ac.ir \\ 'Department of Pathology, Faculty of Veterinary Medicine, Tehran University, Tehran, Iran. \\ ${ }^{2} \mathrm{School}$ of Animal and Veterinary Sciences, the University of Adelaide, Adelaide, Australia. \\ ${ }^{3}$ Graduate, Faculty of Veterinary Medicine, Tehran University, Tehran, Iran. \\ ${ }^{4}$ Department of Clinical Sciences, Faculty of Veterinary Medicine, Tehran University, Tehran.
}

\begin{abstract}
Background: The described pulmonary lesions are compatible with lesions previously described for maedi. In this study, one of the most important ovine slow viral infections is "Maedi disease" which was evaluated in Mashhad province.

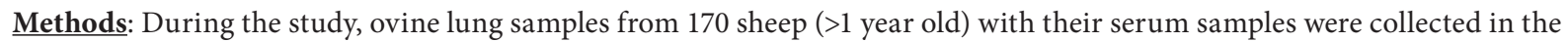
Mashhad industrial abattoir. Initially, histopathological study for lung samples was carried out by providing H\&E staining, serological test and an indirect ELISA on the serum samples. Histopathological study indicated all three lesions of Maedi disease in ovine lung which included smooth muscle hyperplasia (SMH) of alveolar walls, lymphofollicular hyperplasia (LFH) and interstitial pneumonia (IP). Furthermore, some involvement of each lung sample was estimated from mild-moderate and severe.

Results and discussion: Results of histopathological study demonstrated 45 cases (26.5\%) and 15 cases (8.8\%) with moderate degree and severe degree of involvement respectively. Liked-maedi disease included 60 cases (35.3\%) of the whole ovine lung samples. Results of serological study showed 34 positive serums (20.0\%). In addition, 15 cases (8.8\%) of pulmonary lesions which were observed in histopathological study were equal and similar to the lesions previously described for maedi disease, and serological results confirmed them as well. However, there are some pathogens that can cause nearly pathological lesions like maedi in ovine lung.

Conclusion: This study showed that the pathogen causing maedi disease (maedi-visna virus) can be one of the pathogens causing chronic to subacute lymphoid interstitial pneumonia in Iran. Thus, study on histopathological and serological results correlation was performed.
\end{abstract}

Keywords: Maedi disease, histopathological, sheep, serological, abattoir

\section{Introduction}

Maedi and visna are Icelandic words, describing the clinical presentation of two apparently different syndromes that affected Icelandic sheep in the 1940s and 1950s. Maedi, or 'labored Breathing', was a fatal, progressive pneumonia of mature sheep; visna, or 'wasting', was a meningoencephalitis, which caused progressive paralysis and death. The disease was emerged in Iceland during years following the importation of Karakul sheep from Germany in 1933. Its viral aetiology was established in the late 1950s, when it also became obvious that maedi and visna were different syndromes caused by essentially the same virus. The disease was eventually eliminated from Iceland in 1965 following phased destocking of the sheep-rearing areas and repopulation with sheep from unaffected parts of the country. Iceland is the only country that has eradicated maedi-visna (MV) successfully [1-5]. MV virus is a non-oncogenic, exogenous, retrovirus. It belongs to the lentivirus, sub-family of retroviruses and is related to human, simian, feline and bovine immunodeficiency viruses, equine infectious anaemia virus and caprine arthritis encephalitis (CAE) virus. MV and CAE viruses are commonly referred to the small ruminant lentiviruses.
Retroviruses are RNA viruses, which replicate via DNA provirus that becomes integrated or closely linked to genomic DNA in the virus target cells [6]. Histological lesions essentially comprise immunologically mediated chronic active inflammatory changes, with lymphoid infiltration and proliferation in one or more target organs including lung, central nervous system, mammary glands and joints. Main organ-specific changes consist of smooth muscle hyperplasia (lungs), demyelination (central nervous system), fibrosis (mammary gland) and proliferation of synovial membrane, and degenerative changes to the articular cartilage (joints). The clinical respiratory disease causes important economic losses [7-9]. In Iceland, the infection produced a severe clinical disease with losses of up to $30 \%$ in some flocks. In Netherlands, the interstitial pneumonia induced by maedi virus has been the most important economic disease in Dutch flocks.

The routine diagnostic criteria for the disease include the clinical signs, the macroscopic and microscopic lesions, and the detection of antibodies against the virus using the AGID test or the ELISA technique $[4,5,10]$. MV-like diseases have been reported from many of the sheep-rearing countries of the world, whereas nothing was observed in Australia and New Zealand, 
although CAE virus infection occurs in both countries. In the USA, infection is endemic in some of western range flocks, and the associated disease is termed ovine progressive pneumonia, or Montana sheep disease. In the Netherlands, the disease is known historically as zwoergerziekte and in France as la bouhite [1-5,11]. Recent surveys in Spain indicated a high prevalence in some regions [12]. In the UK, it is believed that infection was introduced in the early 1970 s with the importing of breeding sheep from the continent [5]. Furthermore, in Iran, according to one study, the existence of a disease similar to maedi at the morbidity rate of 7.25 , with histopathological evidence of 100 affected ovine lungs in Ahvaz (a town southwest of Iran) was confirmed, nevertheless serological study using AGID test did not produce any positive results [13]. In addition, in pathological study of a 105 samples of ovine lungs, collected on various locations north-east of Iran such as Khorasan province including Mashhad, Dargaz, Fariman and Sarakhs, majority of lesions warranted the existence of maedi ( 15 cases comprising $20.5 \%$ of total samples). The samples showed lymphoproliferative interstitial pneumonia which is an important lesion produced by the virus [14]. The aim of this research was to study pulmonary lesions of maedi in Mashhad for the first time. The assumption of presence or absence of the respiratory disease; maedi, in Mashhad, approximate evaluation of its morbidity among mutton flocks of sheep of this region and evaluation the degrees of consistency between pathological and serological results are of other objectives.

\section{Material and methods}

\section{Geographical area studied}

The study area in this research was Mashhad, a town located in north-east of Iran which receives $57.7 \%$ of total sheep carcasses of the province. Carcasses were sampled from industrial slaughterhouse of this town. The slaughterhouse is located 15 kilometers away from Mashhad in the countryside which supplies more than $95 \%$ of mutton produced in this town.

\section{Sampling procedure}

During the period 2003-2004 sampling procedures was performed as follows: Firstly, the lungs of slaughtered sheep were carefully examined and thereafter 170 lung samples from sheep over 1 year of age, manifesting macroscopic lesions similar to those of maedi from 6 flocks, were selected and tissue sections were prepared from affected portions. Heart blood was also squeezed out by gentle hand pressure in to some serially numbered test tubes.

The samples were selected which simply showed the lesions in the cranial lobes (left and right cranial, accessory lobe and intermediate lobe) and ventral margins, because lesion of maedi are present mostly in these locations in initial steps.

To avoid any partial interpretation of prepared pathology sections which may come from serology results or vice versa, study and interpretation steps were undertaken using a double-blind technique.

\section{Histopathological examination}

Samples from similar anatomic sites of lungs were collected from all selected lungs (of sheep) and processed for conventional histopathological investigation. Samples were also taken from representative parts of other lobes for histopathologic analysis in order to assure uniform distribution of lesions. These pulmonary samples were fixed in $10 \%$ buffered neutral formalin, embedded in paraffin. Two Histological blocks of each tissue sample were prepared and sections $(5 \mu \mathrm{m})$ were obtained with a microtome. These sections were stained with haematoxylin-eosin (H\&E).

Lesions were measured separately by two pathologists grading three parameters: interstitial reaction (IR), smooth muscle hyperplasia (SMH), and lymphoid follicular hyperplasia (FH). IR was defined by the thickening and cellular infiltration of interalveolar septae with lymphocytes and monocytemacrophage cells. The degree of IR and SMH observed in sections from each animal was classified by independent subjective assessment and agreement between two pathologists using the following scale: $0=$ none, $+=$ slight,$++=$ moderate, and $+++=$ severe. In order to analyze IR, a score was applied to each category of lesion: $0=0,+=1,++=2$, and $+++=3$. The SMH was similarly evaluated. The FH was measured by counting the total number of lymphoid follicles in the sections and determining the number of follicles per $\mathrm{cm}^{2}$ of tissue section. The mean surface area studied for each animals was $3.6 \mathrm{~cm}^{2}$ (range 1.9-5) and finally a score was recorded to each category of lesion: $0=$ none, $+=$ slight,++ $=$ moderate, and $+++=$ severe. In addition, more detailed description of this process is described elsewhere. Degree of involvement of each lung sample was estimated from mild to moderate and severe.

\section{Serological examination}

Sera were separated from the heart blood clot samples, aliquoted and stored at $-20^{\circ} \mathrm{C}$ until ELISA were performed. Vacuum tubes and a new needle for every blood sample were used. All the sera were tested with the Institut Pourquier MV indirect ELISA kit (Institut Pourquier,France) according to the manufacturer's instructions.

\section{Data analysis}

To determine whether there were significant differences between variable parameters in this study (age, histopathological and serological results), data were analyzed using the Pearson Chi-Square test. Also study on correlation between histopathological and serological results was statistically performed by using Kappa test.

\section{Results}

Histopathologic examination of affected lungs revealed diffuse lymphoproliferative pneumonia. Within lobules, numerous 


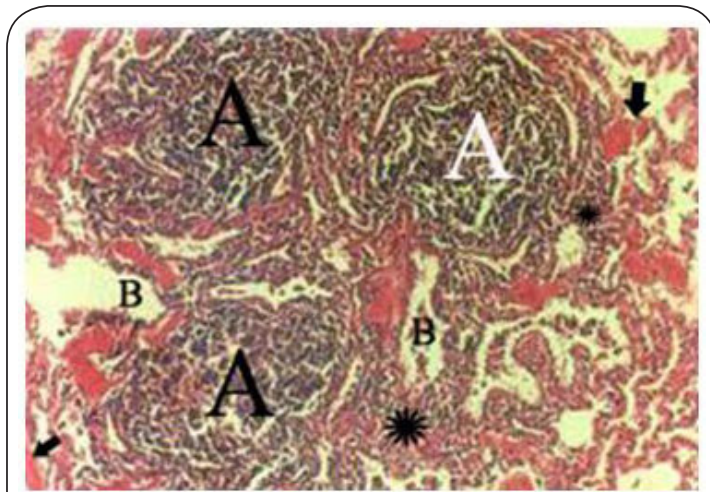

Figure 1. Maedi, x250, (H\&E):

A Infiltration of lymphoctes in to the interalveolar spaces associated with interstitial pneumonia (IP) indicated by asterisk.

- Lymphofollicular hyperplasia (LFH) and bronchioles indicated by $\mathbf{A}$ and $\mathbf{B}$ respectively.

- ${ }^{\star S}$ mooth muscle hyperplasia (SMH) of alveolar wall oF indicated by arrows.

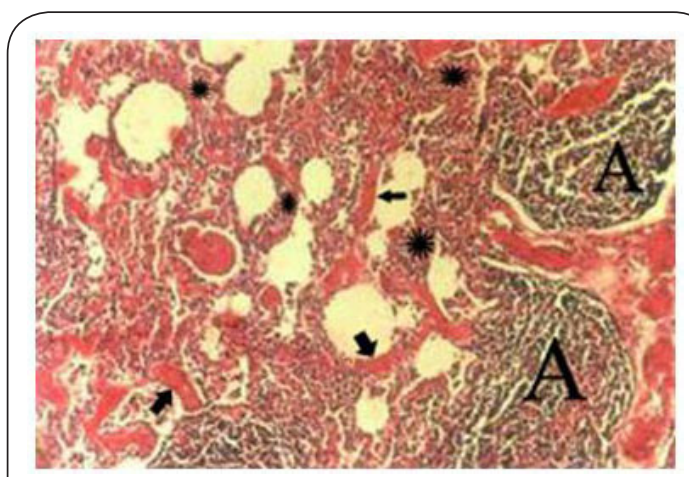

Figure 2. Maedi, x100, (H\&E):

- Infiltration of lymphoctes in to the interalveolar spaces associated with interstitial pneumonia (IP) indicated by asterisk.

- Lymphofollicular hyperplasia (LFH) indicated by $\mathbf{A}$.

- Smooth muscle hyperplasia (SMH) of alveolar walls; indicated by arrows.

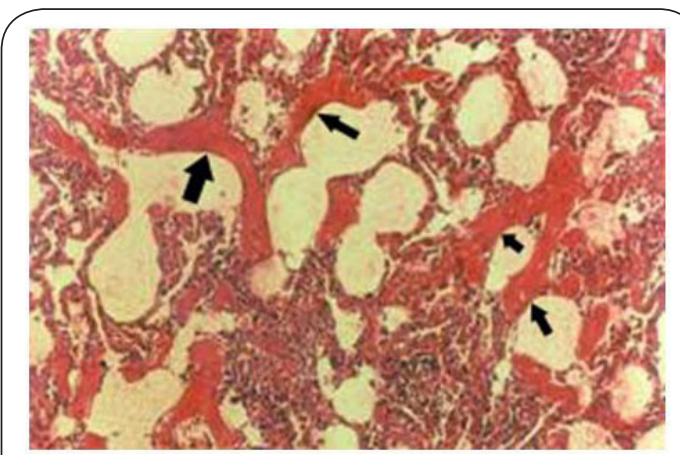

Figure 3. Maedi: smooth muscle hyperplasia of alveolar walls (SMH); indicated by arrows. (Magnification $\times 400),(\mathrm{H} \& \mathrm{E})$.

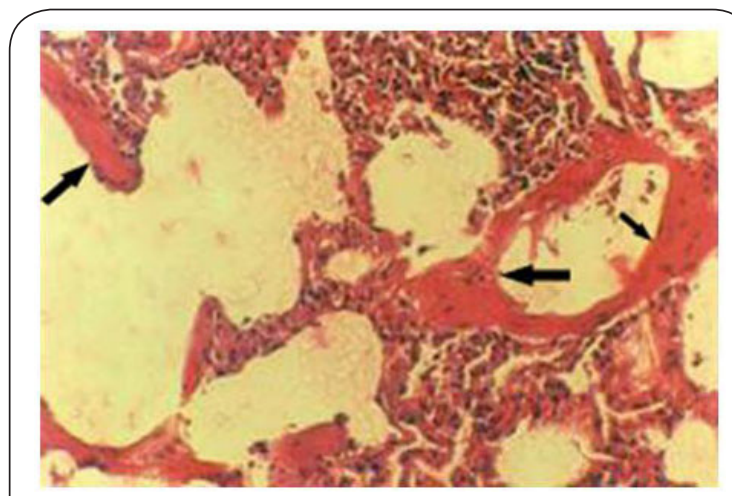

Figure 4. Maedi: smooth muscle hyperplasia of alveolar walls (SMH); indicated by arrows. (Magnification $\times 250)$, (H\&E).

Table 1. Frequency of histopathological results.

\begin{tabular}{lcc}
\hline $\begin{array}{l}\text { Frequency } \\
\text { Histopathological results }\end{array}$ & Relative & Absolute \\
\hline Mild involvement & 110 & 64.7 \\
Moderate involvement & 45 & 26.5 \\
Severe involvement & 15 & 8.8 \\
Sum total & $\mathbf{1 7 0}$ & $\mathbf{1 0 0}$ \\
\hline
\end{tabular}

Table 2. Frequency of serological results.

\begin{tabular}{lcc}
\hline $\begin{array}{l}\text { Frequency } \\
\text { Serological results (ELISA) }\end{array}$ & Relative & Absolute \\
\hline Negative & 136 & 80 \\
Positive & 34 & 20 \\
Sum total & $\mathbf{1 7 0}$ & $\mathbf{1 0 0}$ \\
\hline
\end{tabular}

lymphoid follicles were located adjacent to bronchioles and small vessels, mostly venules (Figure 1). Follicles were also present as discrete nodules apparently unrelated to airways and vessels (Figure 2). Lymphocytes, plasma cells, and macrophages infiltrated into interalveolar septae which resulted in interstitial pneumonia (Figure 1,2). Hyperplasia of perialveolar smooth muscle was also present significantly (Figure 3,4). Results of histopathological study showed 60 cases $(35.3 \%)$ of the whole ovine lung samples that included 45 cases (26.5\%) with moderate degree and 15 cases (8.8\%) with severe degree of involvement in liked-maedi disease (Table 1). Results of serological study indicated 34 positive serums (20.0\%) of the whole ovine serum samples (Table 2). Study on correlating histopathological and serological results was demonstrated that 98 cases (89.1\%) of 110 cases with mild degree of pathological involvement were confirmed by having negative results in serological study. Also 10 cases (66.7\%) of 15 cases with severe degree of pathological involvement were confirmed as positive result in serological study (Table 3). Statistical study showed that the mean age of 


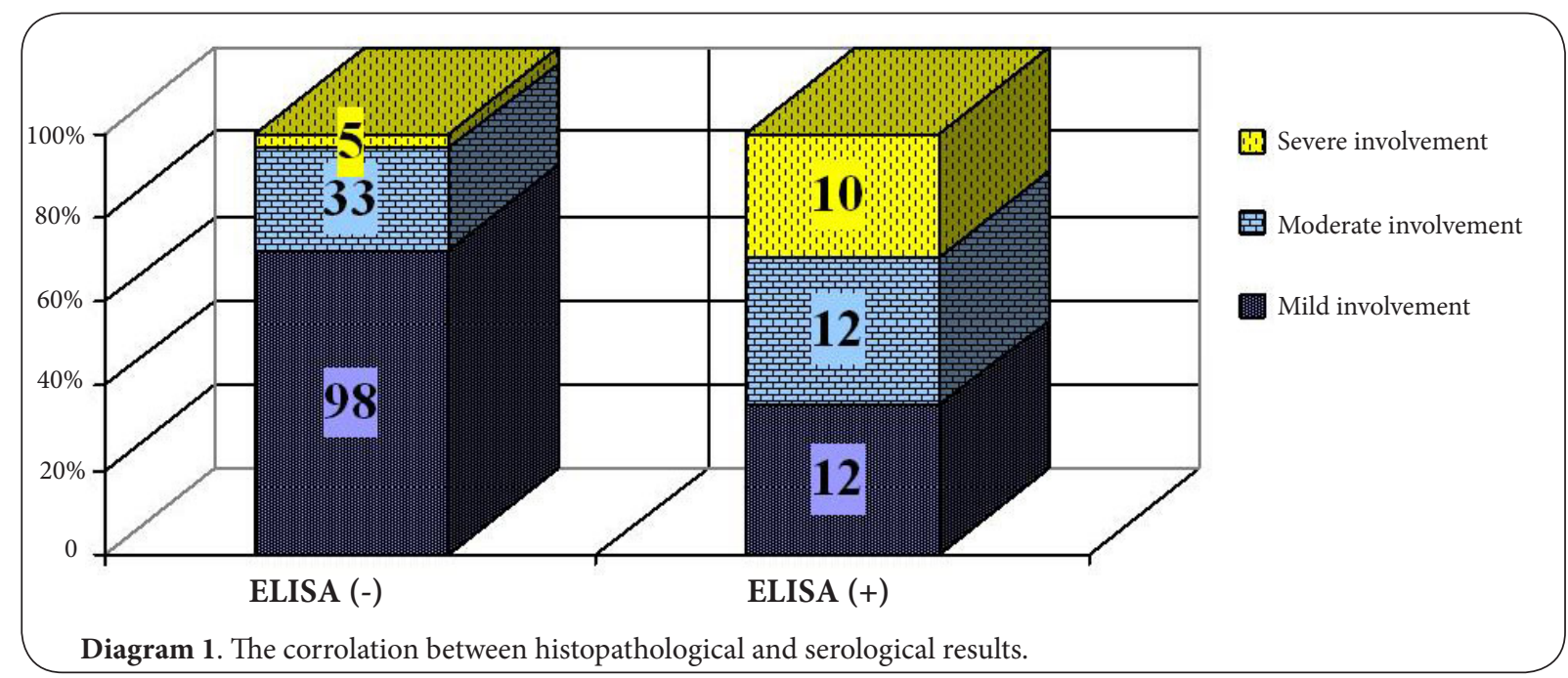

Table 3. Comparative study of histopathology and serology results of samples.

\begin{tabular}{lccc}
\hline $\begin{array}{l}\text { Serological results (ELISA) } \\
\text { Histopathological results }\end{array}$ & Negative & Positive & Total \\
\hline Mild involvement & 98 & 12 & 110 \\
& $(89.1 \%)$ & $(10.9 \%)$ & $(100 \%)$ \\
Moderate involvement & 33 & 12 & 45 \\
& $(73.3 \%)$ & $(26.7 \%)$ & $(100 \%)$ \\
Severe involvement & 5 & 10 & 15 \\
& $(33.3 \%)$ & $(66.7 \%)$ & $(100 \%)$ \\
Total & $\mathbf{1 3 6}$ & $\mathbf{3 4}$ & $\mathbf{1 7 0}$ \\
& $\mathbf{( 8 0 . 0 \% )}$ & $\mathbf{( 2 0 . 0 \% )}$ & $\mathbf{( 1 0 0 \% )}$ \\
\hline
\end{tabular}

sheep having lungs with MV-lesions was significantly more than the mean age of sheep having lungs without MV-lesions $(P<0.0001)$. Also there was a significant difference between histopathological and serological results $(\mathrm{P}<0.0001)$. By using Kappa test there was a moderate correlation (42.47\%) between histopathological and serological results (Diagram 1).

\section{Discussion}

The described pulmonary lesions are compatible with lesions previously described for maedi [15] and are essentially similar to those described for OPP $[16,17]$, and serologically related viruses. The dominant feature was generalized lymphoid hyperplasia with massive peribronchiolar and discrete lymphoid follicles within lobules [7]. These lymphoid nodules were frequently related to small vessels, specifically venules, even in peribronchiolar locations. Infiltration of interalveolar septa appeared to arise as an extension of the peribronchiolar and perivascular cuffing. Bacteria, mycoplasma, or chlamydia were not isolated from lung tissue samples with severe involvement of maedi lesions. In addition, they all belonged to seropositive sheep and included $8.8 \%$ of all 170 samples.

Additionally, significant moderate correlation between histopathological and serological results concluded that when these infections give rise to disease, the lungs seem most frequently involved in the pathologic process; however, other organ systems, including the CNS, joints, mammary glands, and lymphatic system are frequently involved as well [17]. Also study on correlating histopathological and serological results concluded that pathological study on ovine lung is so useful at necropsy for confirming clinical signs [16]. Moreover, remarkable differences between age, histopathological and serological results in statistical study of these whole 170 samples confirmed this suggestion completely. Similar attempts to assess the relationship between these parameters in Spain [12] and in Morocco [18] showed the same percentages and results as well. Thus, importance of sampling from ovine lungs must be considered to continue the program of recognizing and controlling this viral infection $[12,19]$.

\section{Conclusion}

Our results demonstrated the high prevalence of infection associated with pathological respiratory disease in this area that was confirmed by seropositive results. Actually, the pathogen causing maedi disease (maedi-visna virus) can be one of the pathogens causing lymphoid interstitial pneumonia in Iran.

Consequently, we were not able to detect maedi lesions in 5 seronegative animals. However, the pathological and clinical signs of maedi infection are not pathogenomic and other chronic diseases may trigger them $[\mathbf{2 0 , 2 1 ]}$.

\section{Competing interests}

The authors declare that they have no competing interests.

\section{Authors' contributions}

FS participated in the histopathological evaluation, performed the literature review, acquired photomicrographs and drafted the manuscript and gave the final histopathological diagnosis. $\mathrm{JJ}$ performed sequencing alignment and manuscript writing. 
FH and MRM concieved, designed, acquired data, analyzed \& interpreted, statistical analysis \& drafted the manuscript. $\mathrm{MAH}$ edited the manuscript and made required changes. All authors have read and approved the final manuscript.

\section{Acknowledgement}

The authors thank staff of the Department of pathology, Faculty of Veterinary Medicine, Tehran University for their valuable technical assistance.

\section{Publication history}

Editor: Ishtiaq Qadri, King Abdul Aziz University, Saudi Arabia. EIC: Ishtiaq Qadri, King Abdul Aziz University, Saudi Arabia. Received: 07-Jun-2013 Revised: 12-Jul-2013

Accepted: 24-Jul-2013 Published: 30-Jul-2013

\section{References}

1. de la Concha-Bermejillo A. Maedi-Visna and ovine progressive pneumonia. Vet Clin North Am Food Anim Pract. 1997; 13:13-33. | PubMed

2. Pepin M, Vitu C, Russo P, Mornex JF and Peterhans E. Maedi-visna virus infection in sheep: a review. Vet Res. 1998; 29:341-67. | PubMed

3. Murphy F A, Gibbs E P J, Horzinek M C and Studdert M J. Laboratory Diagnosis of viral diseases. Veterinary virology. 3rd ed. San Diego, Calif:Academic Press. 1999; 193-224.

4. Radostits OM, Gay CC, Blood DC and Hinchcliff KW. Ovine progressive Pneumonia (Maedi, Maedi-Visna). Veterinary Medicine. 9th ed. W.B. Saunders Company Ltd., London, 2000; 1186-1189.

5. Martin WB and Aitken ID. Diseases of sheep. Blackwell science. 3rd ed. 2002; pp:187-191. | Book

6. Cutlip RC, Lehmkuhl HD, Schmerr MJ and Brogden KA. Ovine progressive pneumonia (maedi-visna) in sheep. Vet Microbiol. 1988; 17:237-50. | Article I PubMed

7. Dawson M. Pathogenesis of maedi-visna. Vet Rec. 1987; 120:451-4. Article | PubMed

8. Jubb KVF, Kennedy PC and Palmer N. Pathology of domestic animals. 4th ed. Academic Press: San Diego, California, USA 1993; 3: 653. | Book

9. McGavin DM, Carlton WW, Zachary JF. Thomson's Special Veterinary Pathology, 3rd ed. Mosby, 2001; 96-97. I Book

10. Oliver RE, Gorham JR, Parish SF, Hadlow WJ and Narayan O. Ovine progressive pneumonia: pathologic and virologic studies on the naturally occurring disease. Am J Vet Res. 1981; 42:1554-9. I PubMed

11. Carey $\mathrm{N}$ and Dalziel RG. The biology of maedi-visna virus--an overview. Br Vet J. 1993; 149:437-54. | $\underline{\text { Article | PubMed }}$

12. Lujan L, Begara I, Collie DD and Watt NJ. CD8+ lymphocytes in bronchoalveolar lavage and blood: in vivo indicators of lung pathology caused by maedi-visna virus. Vet Immunol Immunopathol. 1995; 49:89100. I Article | PubMed

13. Georgsson $\mathrm{G}$ and Palsson PA. The histopathology of maedi a slow, viral pneumonia of sheep. Vet Pathol. 1971; 8:63-80. | PubMed

14. Marsh H. Progressive pneumonia in sheep. J Am Vet Assoc. 1923; 62:458-473. | Article

15. Bouljihad $M$ and Leipold HW. Ovine lentiviral infection (maedi/visna) in Morocco: a serologic and postmortem survey. Zentralb/Veterinarmed $A$ 1994; 41:317-28. | Article | PubMed

16. Capucchio MT, Sanna E, Sanna MP, Farigu S, Minelli R and Guarda F. Maedi-visna virus detection in ovine third eyelids. J Comp Pathol. 2003; 129:37-43. | Article | PubMed

17. Gharagozlou MJ, Tabatabayi AH and Forci M. Pathology of ovine subacute to chronic pneumonia associated with mycoplasma arginini in Iran. Studies and Researches in Veterinary Medicine. 1986; 1: 25-31.

18. Kimberling CV. Jenson and Swift's. Diseases of Sheep. 3rd ed. Philadelphia. Lea. \&Febiger, 1988; 274-280. | Book
19. Houwers DJ, Gielkens AL and Schaake J, Jr. An indirect enzyme-linked immunosorbent assay (ELISA) for the detection of antibodies to maedivisna virus. Vet Microbiol. 1982; 7:209-19. | Article | PubMed

20. Smith BP. Large Animal Internal Medicine. 3rd ed. St. Louis: Mosby, Inc., 2001; 171-181. | Book

21. Tabatabayi AH, Gharagozlou MJ and Ghader-Sohi A. A survey of Mycoplasma arginini and other agents from subacute and chronic ovine pneumonia in Iran. Prev Vet Med. 1992; 12:153-158. | Article

\section{Citation:}

Sasani F, Javanbakht J, Hemmatzadeh F, Rajabi-Moghadam $\mathrm{M}$ and Aghamohammad Hassan M. Evaluation of histopathological on maedi disease with serological confirmation in North-East of Iran. Res J Infect Dis. 2013; 1:5. http://dx.doi.org/10.7243/2052-5958-1-5 